\title{
Togetherness of Ebstein anomaly and giant hairy nevus in a neonate: first case in the literature
}

\author{
Ferda Özlü ${ }^{1}$, Mahmut Tülüce ${ }^{2}$, Mehmet Satar ${ }^{1}$, Nazan Özbarlas ${ }^{3}$, Banu Kozanoğlư \\ Aydın Yücel ${ }^{5}$ \\ ${ }^{1}$ Divisions of Neonatology, ${ }^{3}$ Cardiology and ${ }^{4}$ Oncology, Department of ${ }^{2}$ Pediatrics and ${ }^{5}$ Department of Dermatology, \\ Çukurova University Faculty of Medicine, Adana, Turkey. \\ E- mail: ferdaozlu72@yahoo.com \\ Received: 2nd October 2017, Accepted: 18th November 2017
}

\begin{abstract}
SUMMARY: Özlü F, Tülüce M, Satar M, Özbarlas N, Kozanoğlu B, Yücel A. Togetherness of Ebstein anomaly and giant hairy nevus in a neonate: first case in the literature. Turk J Pediatr 2018; 60: 744-746.
\end{abstract}

Ebstein anomaly is a congenital heart defect in which the septal and posterior leaflets of the tricuspid valve are displaced through the apex of the right ventricle. Giant congenital melanocytic nevi originate from melanocytes. It is usually seen after birth. Here we present the first neonate with prenatally diagnosed with Ebstein anomaly with giant hairy nevus in the literature.

Key words: neonate, Ebstein anomaly, giant hairy nevus.

Ebstein anomaly is a congenital heart defect in which the septal and posterior leaflets of the tricuspid valve are displaced through the apex of the right ventricle. This leads to the atrialization of a portion of the right ventricle which causes the right atrium to be large and the anatomic right ventricle to be small in size. The incidence of this anomaly is $<1 \%$ among all congenital heart defects. ${ }^{1}$ Due to the narrowing of right ventricle, ductus arteriozus may be obligatory for pulmonary blood flow at early hours after birth. ${ }^{2}$

The congenital melanocytic nevus, denotes a pigmented surface lesion present at birth. Using the prediction classification, giant nevi have been described in children as comprising $9 \mathrm{~cm}$ on a child's head and $6 \mathrm{~cm}$ on a child's body. ${ }^{3}$ Very large congenital nevi account for less than $0.1 \%$ of cutaneous melanomas. ${ }^{4}$

Here we present a neonate with prenatally diagnosed Ebstein anomaly with giant hairy nevus comprising more than $50 \%$ of the body. This is the only case in literature describing these two pathologies in the same neonate.

\section{Case Report}

A 2790 g girl infant was born vaginally at the 39 th gestational weeks. The 29 year old mother had hypothyroidism and gestational diabetes mellitus. Parents were nonconsangenius. On fetal ecocardiography, she was diagnosed with Ebstein anomaly. There were not any antenatal risk factors such as medication, radiation or demonstrated disease. The Apgar scores were 9 and 10 at first and fifth minutes. On physical examination; tachypnea, $3 / 6^{\circ}$ systolic murmur and giant hairy melanocytic nevus were pathologic findings (Fig. 1 and Fig. 2). The echocardiograpy yielded Ebstein anomaly, PDA, large ASD, tricuspid valve insufficiency on postnatal first day. (Fig. 3.) ECG showed tall and broad $P$ waves as a result of right atrial enlargement. Due to desaturation of the baby below $75 \%$, prostaglandin $\mathrm{E}_{1}$ infusion was started. She was consulted with dermatology, pediatric oncology and the genetics divisions. $\mathrm{N}$-RAS mutations were negative, $\alpha$-feta protein, carcinoembriyonic antigens were within normal limits. On follow-up, prostaglandin was stopped at the 10th day of life. Cranial and abdominal ultrasonographs were normal. Her

This case report was presented at 28th Annual Meeting of the European Society of Paediatric and Neonatal Intensive Care (ESPNIC 6-9 June 2017) Lisbon, Portugal. 


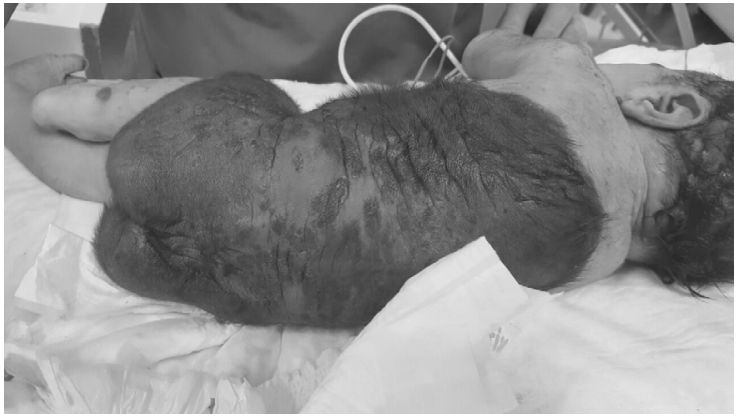

Fig. 1. Physical apperance of the infant with giant hairy nevus.

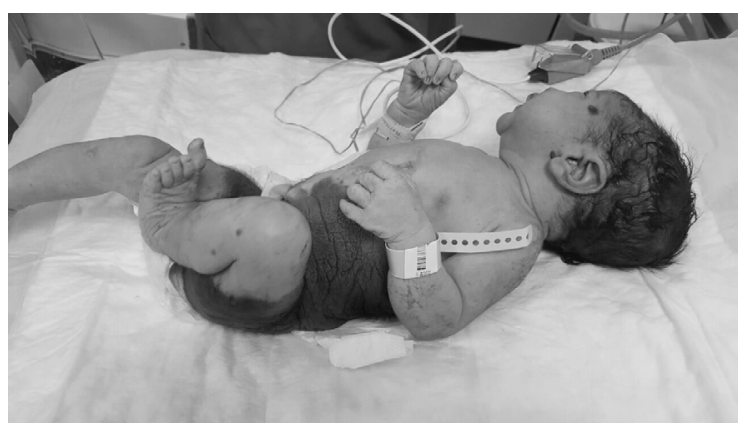

Fig. 2. Giant hairy nevus of the infant.

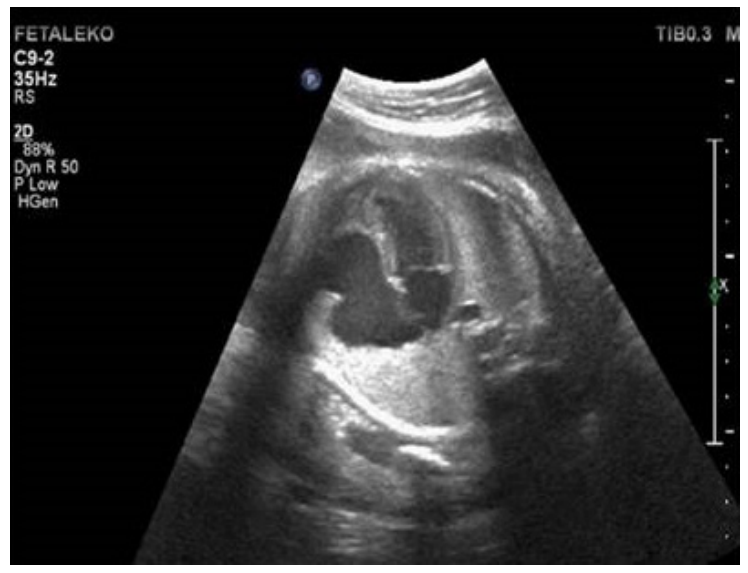

Fig. 3. Fetal cardiac four chamber view shows significant tricuspid valve displacement toward the apex.

cardiac hemodynamic status was good. On the 18th day of life her weight, height and head circumference were in 75-90 percentile. She was referred to the outpatient clinics of pediatric cardiology, dermatology, plastic surgery without any medication for follow-up. Cranial and spinal MR has been planned for the 5th month of life. Parents provided informed consent.

\section{Discussion}

Ebstein anomaly is a rare congenital heart disorder occurring in about $1-5$ of 200,000 live births ${ }^{1}$. There are heterogeneous genetic factors in Ebstein anomaly. Case-control studies suggest genetic, reproductive, and environmental risk factors. ${ }^{5}$ Maternal lithium therapy can rarely lead to Ebstein anomaly in the offspring ${ }^{1}$. Most cases are sporadic; familial Ebstein anomaly is rare. The mother of our case did not receive lithium therapy and there was not a history of any other case of Ebstein anomaly in the family.

Digilio et al. ${ }^{6}$ reported that in 44 Ebstein anomaly patients, twelve $(27 \%)$ were diagnosed with a syndrome, and seven of those patients were diagnosed with distinct disorders, including CHARGE syndrome in two, and VACTERL association, Noonan syndrome, Kabuki syndrome, Holt-Oram syndrome, and Cornelia de Lange syndrome in one each. Our patients did not have any features of these syndromes. Digilio et al. ${ }^{6}$ also reported that of the 32 patients with nonsyndromic Ebstein anomaly, ten (31\%) had additional congenital heart defects, including seven atrial septal defects (ASD), two ventricular septal defects (VSD), two pulmonary stenoses, one dextrocardia, one aortic coarctation, and one patent ductus arteriosus (PDA). Patients with Ebstein anomaly also have conduction system abnormalities, which are at least partly due to the compression of the AV node by the septal malformation, accessory pathways, and abnormalities of the right bundle branch. ${ }^{1}$ Our patient had ASD, PDA as additional cardiac defects but she did not have an arrhythmia.

Congenital melanocytic nevus syndrome is characterized by pigmentary skin defects apparent at birth. Congenital melanocytic nevus syndrome (CMNS) is caused by somatic mutation in the NRAS gene on chromosome $1 \mathrm{p} 13 .{ }^{7}$ This mutation was negative in our patient. Most individuals have 1 or more large or giant lesions greater than $20 \mathrm{~cm}$ and up to over $60 \mathrm{~cm}$ in diameter. ${ }^{4}$ One of the serious complications of GCMN is malignant melanoma. ${ }^{8}$ Our patient is on follow up for melanoma.

Case reports have present individuals with giant congenital melanocytic nevus, to have additional diffuse lipomatosis, urinary tract anomalies, and capillary vascular malformations. ${ }^{9}$

This is the first neonate in the literature 
having both Ebstein anomaly and giant hairy nevus. This association could be coincidental or components of a new association.

\section{REFERENCES}

1. Attenhofer Jost $\mathrm{CH}$, Connolly HM, Dearani JA, Edwards WD, Danielson GK. Ebstein's anomaly. Circulation 2007; 115: 277-285.

2. Rao PS. Consensus on timing of intervention for common congenital heart diseases: Part II - cyanotic heart defects. Indian J Pediatr 2013; 80: 663-674.

3. Mutti LA, Mascarenhas MRM, Paiva JMG, Golcman R, Enokihara MY, Golcman B. Giant congenital melanocytic nevi: 40 years of experience with the serial excision technique. An Bras Dermatol 2017; 92: 256-259.

4. Melanocytic Nevus Syndrome, Congenital; Cmns. Erişim adresi: https://www.ncbi.nlm.nih.gov/omim/ term $=137550$ (Erişim Tarihi:02.10.2017)
5. Miller MS, Rao PN, Dudovitz RN, Falk RE. Ebstein anomaly and duplication of the distal arm of chromosome 15: Report of two patients. Am J Med Genet A 2005; 139A: 141-145.

6. Digilio MC, Bernardini L, Lepri F, et al. Ebstein anomaly: Genetic heterogeneity and association with microdeletions $1 \mathrm{p} 36$ and 8p23.1. Am J Med Genet 2011; 155A: 2196-2202.

7. Dessars B, De Raeve LE, Morandini R, et al. Genotypic and gene expression studies in congenital melanocytic nevi: Insight into initial steps of melanotumorigenesis. J Invest Dermatol 2009; 129: 139-147.

8. Maguire CR, Livingston R, Phillips GE, Kimble RM. Giant congenital melanocytic nevi and malignant transformation: A case for early radical intervention. Pediatr Surg Int 2017; 33: 823-827.

9. Viana AC, Gontijo B, Bittencourt FV. Giant congenital melanocytic nevus. An Bras Dermatol 2013; 88: 863878. 